\title{
How computational chemistry develops: a tribute to Peter Goodford
}

\author{
Gabriele Cruciani ${ }^{1} \cdot$ Yvonne Martin ${ }^{2} \cdot$ Andy Vinter $^{3} \cdot$ Richard Lewis $^{4} \cdot$ Federico Gago $^{5} \cdot$ Terry R. Stouch $^{6}$
}

Published online: 21 August 2019

(c) Springer Nature Switzerland AG 2019

\section{Abstract}

This editorial discusses the foundation of aspects of computational chemistry and is a tribute to Peter Goodford, one of those founders, who recently passed away. Several colleagues describe Professor Goodford's work and the person himself.

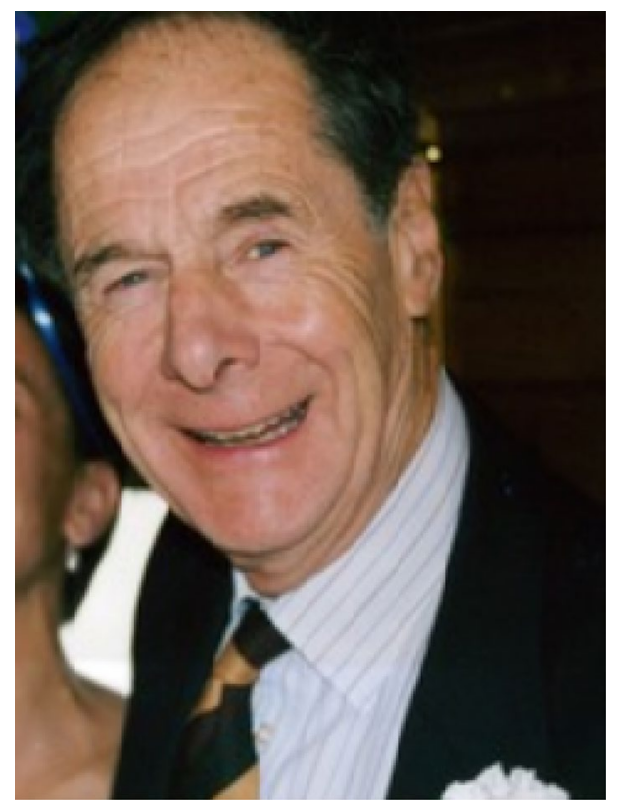

Fig. 1 A recent picture of Peter Goodford (picture thanks to Professor Gabriele Cruciani)

Yvonne Martin: Retired.

\section{Terry R. Stouch}

tstouch@gmail.com

1 University of Perugia, Perugia, Italy

2 Abbvie, North Chicago, Illinois, USA

3 Cresset-Group, Welwyn Garden City, UK

4 Novartis, Basel, Switzerland

5 University of Alcalá, Madrid, Spain

6 Science For Solutions, LLC, Princeton Junction, New Jersey, United States
Keywords Peter Goodford · Tribute · Grid · International School of Crystallography $\cdot$ Oxford $\cdot$ Erice $\cdot$ Founder

\section{Terry Stouch}

Many of us are mourning a friend in the loss of Peter Goodford. But that is not the only reason for this editorial. The loss of a friend matters to those few of us who knew him. However, the contributions of a pioneer and visionary in our field of computer-aided drug design impacts all of us.

And as one of the founders of the application of methods of our field, Peter's accomplishments started from scratch. He envisioned something different and new and what needed to be done to achieve it. He was driven to make it work.

And like most of our founders, he didn't depend on computers, he worked from the basics of physics, biology, and chemistry at a time when computers were rare, expensive, slow, and had only a tiny fraction of the memory we have now. Archives were, at best, put on large rolls of magnetic tape accommodating a few megabytes; but then, relative to the scant amount available data in those times, that was not so bad. The founders used what data they could find and added substantial thought and perhaps some dreams in order to make their successes. They had to, there was no other option.

How many of the rest of us work from the basics rather than running software that includes approximations and errors that are largely unknown to us? Let's appreciate the past and honor the ones who got things started for us. However, we now have much more data, much more knowledge, and phenomenally more computation (even in our pockets no less). Should we rely on the past? Or should we think like our founders and use our much larger trough of data and the relatively phenomenal computation resources and start anew from the basics? Some of our colleagues are doing this now. 
Let's not let them do so alone. Indeed, many of our founders have improved their methods many times.

As an example, early force fields were made for building static molecular models that matched crystal structures. However, those structures contained kinetic energy implicitly which allowed the atoms to fit in the (often room temperature) crystal structures by giving them sufficient size to fill the space as seen in the crystals. However, those force fields were not made for molecular dynamics which incorporates kinetic energy explicitly. Hence atoms were effectively too large and the densities of the atom systems were substantially too large. Substantial corrections or complete redevelopment of those force fields were required. As we expect more and more detail and precision, how much more needs to be done? How might our work be affected by the errors and approximations of the old and even the new software and approaches?

Finally, while there is time and if you have the opportunity, talk to our founders. I've found that many of them are very willing to relay the science of the past, present, and their vision of the future, not to mention some great stories to tell.

But enough from me, following are a number of insights into Peter's science and accomplishments.

\section{Gabriele Cruciani, student, colleague and friend of Peter}

\section{Peter Goodford, a pioneer of structure based drug design and molecular interaction fields}

Peter Goodford was preparing a course of lectures on "Blood" for medical students at the Royal London Hospital in 1965, when he learned how Max Perutz in Cambridge was using X-ray crystallography to determine the structure of the haemoglobin tetramer ( $\mathrm{Hb} 4)$. He thought that macromolecular structures like Perutz's Hb4 could possibly be used as scaffolds to design novel therapeutic agents, but he very soon realised that it might be difficult to examine such an unsubstantiated hypothesis in the clinical environment of a teaching hospital.

Goodford therefore moved to the pharmaceutical industry in 1967, and was appointed head of a new "Department of Biophysics and Biochemistry" at the Wellcome Research Laboratories near London. By the early 1970s he had convinced Wellcome's research director, John Vane, that the scaffold hypothesis should be tested, and that Wellcome should establish a laboratory for the X-ray crystallography of proteins. Max Perutz in Cambridge; David Phillips in Oxford; Herman Watson in Bristol, and Tom Blundell at the University of Sussex all provided active support for this project, and Goodford recruited crystallographers (John Champness, Christopher Beddell, and David Stammers) from these academic groups.

During the 1980s Goodford retired from Wellcome, and went to live with his family in a village outside Oxford and used his savings to buy a small VAX VMS DEC computer for his study at home. Goodford did not believe that it was possible to "design" therapeutic agents. He reserved this word for cars, railway tunnels, knives, forks and anything whose ideal properties could be precisely and completely specified on paper before it was actually made. In his view it was not normally possible to synthesis novel drug molecules with precisely defined ideal properties, and he would sometimes emphasis this opinion by asking colleagues how they would design and synthesis a flat methane molecule.

In Goodford's opinion suitable molecules for a specific therapeutic job could sometimes be "discovered", and he thought that computational studies would be an aid in the discovery process. He believed that the findings could help with the generation of new concepts, and thus lead to the discovery of novel compounds for biological testing. He thought that computer programs should not simply deliver numbers (which might or might not be correct), but should promote new creative exploitable ideas in the mind of the user.

Goodford had this objective in mind when he devised his well-known GRID program as a tool for anyone studying a "Target" molecule of known structure (such as Hb4). GRID would draw the user's attention to places on the Target where a particular atom or chemical group (known as the "Probe") should interact favourably. Probes could be monatomic (e.g. carbonyl oxygen) or more complex (e.g. a complete amide group CO-NH2) or conceptual (e.g., The Hydrophobic Probe), and the user had to decide which Probe or Probes he or she would like to study. He might, for example, select an aliphatic hydroxyl Probe if he wanted to synthesis sugar molecules, or a carboxyl Probe if he thought that acidic ligands would be appropriate for the chosen Target. However, the use of GRID would more or less force him to think seriously about the structure and properties of both Target and Ligand.

The American scientist Yvonne Martin heard about GRID during the 1980s, and invited Goodford to install a copy of the program in her laboratory. This was the start of a collaboration during which Peter came to realize that many people world-wide might be interested in the GRID method. Before long the program had been ported to other hardware platforms, and there were GRID users on every continent. Peter became a frequent visitor at academic departments from Barcelona to Sydney; from Helsinki to San Diego, and at pharmaceutical companies from Cincinnati to Osaka; from Berlin to Melbourne. In 1989 an "International School of Crystallography" was organised by Peter at Erice, and a powerful Silicon Graphics computer was lugged up the 
second highest mountain in Sicily so that participants could try out the software for themselves. Installing that computer at that time, and getting it to work in such an isolated location, was a significant achievement for Silicon Graphics, and it is sobering to think that almost every participant could bring his own powerful notebook to the corresponding Erice school only twenty years later.

Goodford took the view that the success of a drug discovery project could only be judged by the number of new medicines which it spawned, and by the therapeutic success of those novel compounds in helping sick people in the real world. He was very excited when Glaxo used GRID in the discovery of their anti-flu drug Relenza, the first of few real drugs designed with his method. Peter himself continued devising novel GRID algorithms for more complex Probes and for more flexible Targets till the year 2006 with the help of young scientists expert in modern methods of drug discovery and coming from all over the world.

\section{Yvonne Martin}

Peter Goodford was truly the pioneer of structure-based drug design. He had the vision to recognize the potential of using 3D protein structures for drug design and the determination to pursue it in an era in which there were no computer graphics programs to visualize the structure and in which there were very few 3D protein structures to use (Figure 1).

I first heard about this work in 1976 at the European QSAR Symposium. There Frank Norrington described the Wellcome Research Laboratories program that used a physical model of the protein to design compounds that modulate the release of oxygen from haemoglobin. He kindly sent me photographs of the model in the oxy- and desoxy conformations, which I kept on my office wall for many decades. This ground-breaking work was published that year. "Compounds designed to fit a site of known structure in haemoglobin" (https://doi.org/10.1111/j.1476-5381.1976.tb07468.x). All three designed compounds were active. Figure 2 shows the structures of diphosphoglycerate and the most potent compound.
It is interesting that this article is not well known: According to a Google Scholar search conducted on June 7, 2019, it was cited 122 times. It was truly a publication ahead of its time. In contrast, the publication that describes Goodford's ground-breaking program GRID netted 3018 citations.

After the hemoglobin work, Wellcome turned their attention to dihydrofolate reductase (https://doi. org/10.1016/0014-5793(81)81,030-7 and https://doi. org/10.1021/jm00381a008). It was the challenges of this work that led Peter to invent the program GRID, which provides a visual guide to scientists to design ligands for proteins.

\section{Andy Vinter: Cresset-Group}

You cannot "comment" about Peter-indifference was not an option. He was indeed a 'Marmite' of a character, drawing loyal scientists around him but spawning enemies from those who dared to question his science or show lack of imagination. Because Peter was not my direst boss at Wellcome, I never got close enough to define this very clever, complicated man-able to be utterly charming on Tuesday and devastatingly fearsome on Wednesday. Peter Goodford was one of the earliest pioneers-and maybe the first- to introduce X-ray crystallography into the UK pharmaceutical industry. He was a visionary in this respect but, in the 70 s, the cost and time needed to maintain the technology far outweighed its perceived usefulness and ultimately lead to Peter's departure from Wellcome in the early 80s. What we all appreciated during those times was Peter's total belief in his science and the way he used his formidable strength of character to defend it. Many of us junior staffers learnt a great deal from Peter but were not privy to the higher politics. Thirty years on, we can better appreciate what obstacles Peter had to overcome to establish his vision and understand why he could be lovable and scary all at the same time! We have lost a dedicated scientist who was powerful, influential and ahead of his time. He knew he was right-and he was! The technology was yet to catch him up.
Fig. 2 The structure of diphosphoglycerate and the most potent compound
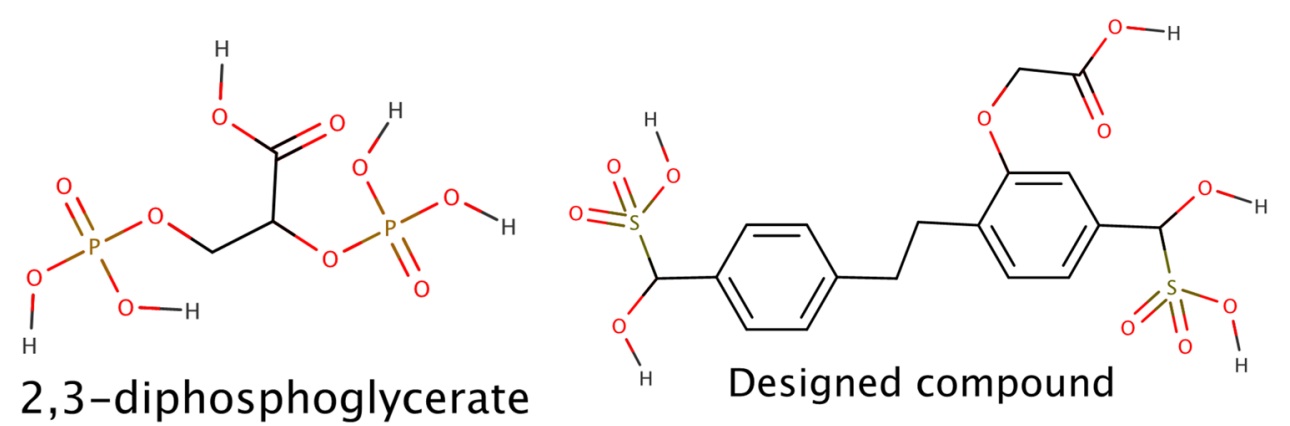
Peter was an imposing figure and, with his outsized summertime Safari suit on, my lasting memory is of him approaching me across the canteen floor in full sail at speed, lunch tray in hand, with no means of escape for me. As it happened, we talked 'DHFR' and it was delightful.

\section{Richard Lewis}

We are mourning the passing of one of the great figures in the field of molecular modelling, Peter Goodford. We all have many happy memories of Peter, not just because of his piercing insights into the issues of modelling, but also the gentleness with which he passed those insights on. He taught us to think and question at every step, rather than rely on assumptions. Many of us joked that he had woven some of that personality into the early versions of GRID, which had a long question at every step, asking whether we really wanted to protonate this residue or remove those waters. Peter was every inch the English gentleman: polite, well-mannered and with a great sense of humor.

For many of us, the first time we really got to see Peter the scientist was at the 1989 International School of Crystallography conference: "Three Dimensional Molecular Structure and Drug Action" in Erice, Sicily, Italy which he chaired (Fig. 3). It was meeting that brought together crystallographers, cheminformatics and modelers, to form a rounded community; the cadre of attendees has provided many of today's leaders in molecular design. It was almost like that Peter had picked people whom he thought might shape the future. At the end of the meeting Peter laid out a set of challenges (Fig. 4). It says much about his foresightedness, that most are still relevant today.

If we can see further today, it is because we are standing on the shoulders of a giant.

\section{Federico Gago}

Peter cast a long shadow during the peak of his scientific career, both at Wellcome in London and the Rex Richards Building at Oxford, and his influence in the CADD field has been profound. I remember him during the years 1987-1989 entering room 268 at the PCL to try his GRID program at a pioneering PERQ (from "perquisite") personal workstation on which Graham Richards' students (Dave Ricketts, Clare Macrae and Garret Morris, among others) also tested some interesting codes that would later develop into some of the core applications marketed by Oxford Molecular Ltd. The first Silicon Graphics workstation would soon follow in Graham's lab (an Iris 3120), and Peter was quick in realizing

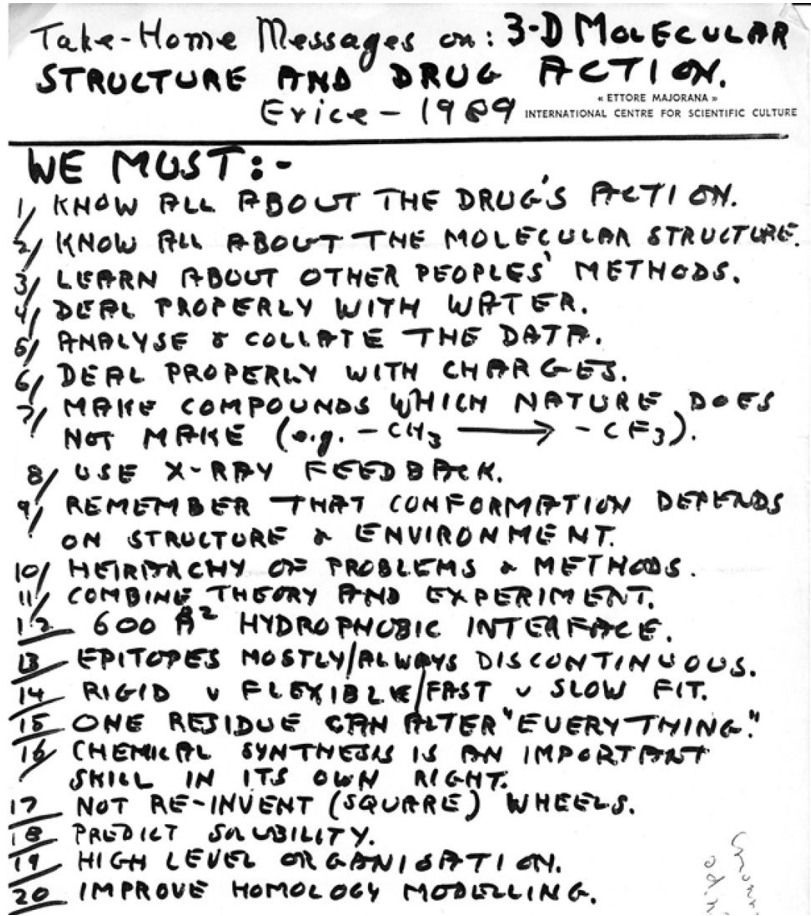

Fig. 3 Peter's list of set of challenges during the 1989 meeting at Erice

that these pieces of equipment would soon supersede the Evans \& Sutherland vector graphics colour displays that were in vogue in X-ray crystallography laboratories at the time. After my return to Alcalá in Madrid, I received a copy of every single release of the GRID code on a cartridge tape together with a friendly handwritten note from Peter. He was always a constant, albeit spatially distant, presence in my lab.

In this necessarily brief remembrance, I would like to mention Peter's relentlessness when facing a scientific problem and his characteristic gentlemanly behaviour under all circumstances. An example of the latter was early given to me when, after one of my very first seminars at the PCL, he whispered to me: "Fred, the next time you show that slide, turn it over because the DNA you presented appears left-handed and it is surely B-DNA you are talking about". Other personal recollections abound, and I can only express my gratitude for his guidance and affection. On the scientific side, I would like to bring up some sentences extracted from his prescient paper entitled "Drug Design by the Method of Receptor Fit" (1984) published in the Journal of Medicinal Chemistry:

What, then, does the method of receptor fit offer for a future in which the structure and function of macro- 
Fig. 4 The attendees at the 1989 International School of Crystallography conference: "Three Dimensional Molecular Structure and Drug Action" (Picture thanks to the International School of Crystallography and https://crystalerice.org/Pasta ctivity/1989/1989.htm)

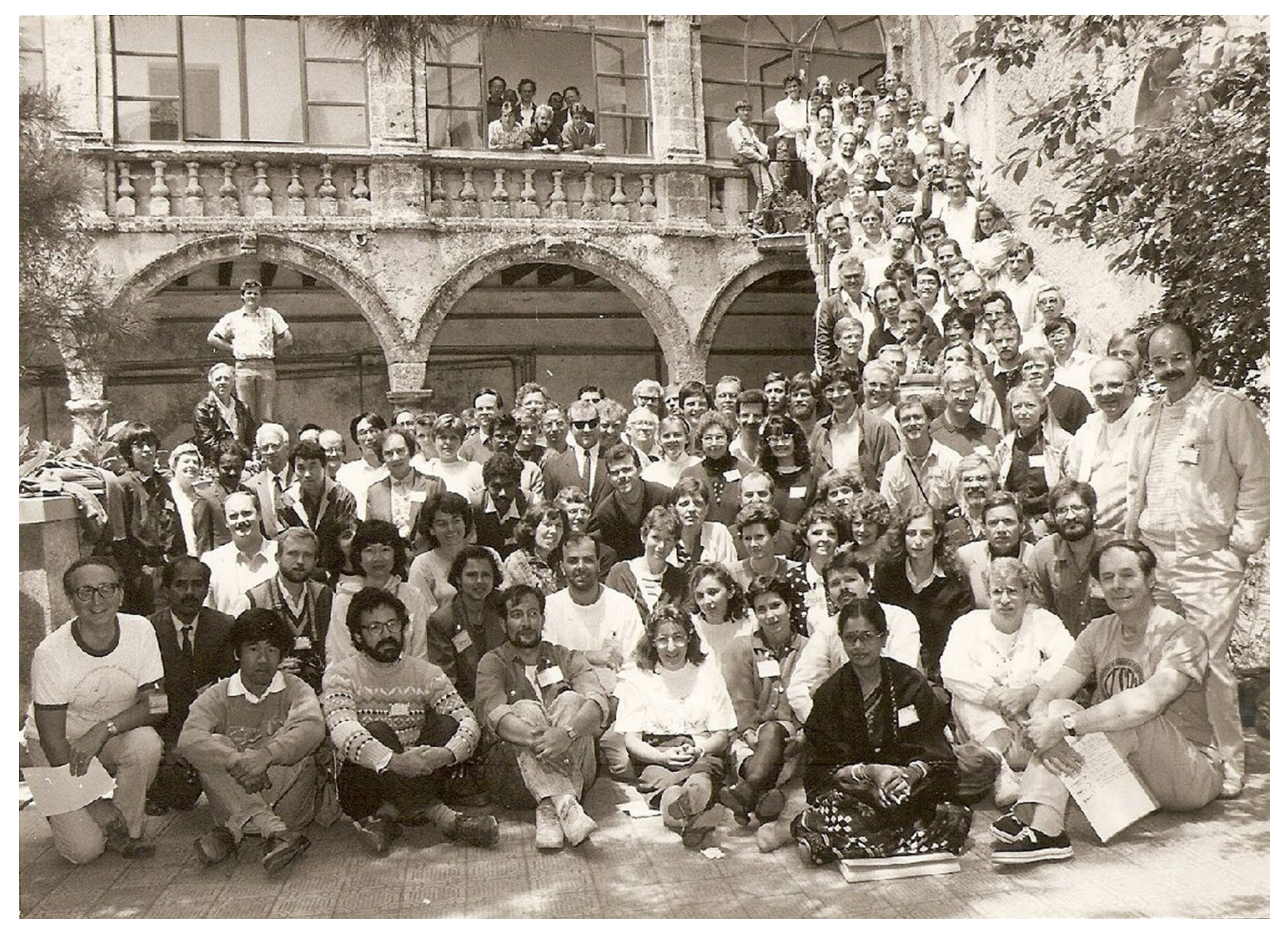

molecules will be understood and where doctors may have direct access to the full genetic code of every patient?

Sequence variation may be exploited to improve specificity, because systematic differences of protein sequence can often be detected near ligand binding sites.

All receptors are different until proved identical.

One last conclusion seems very probable. Mountaineers climb because the mountains are there and offer them a worthwhile challenge, and scientists will try to design drugs to fit receptors for similar reasons.

And, finally, a good-willed farewell in his own handwriting (Fig. 5).

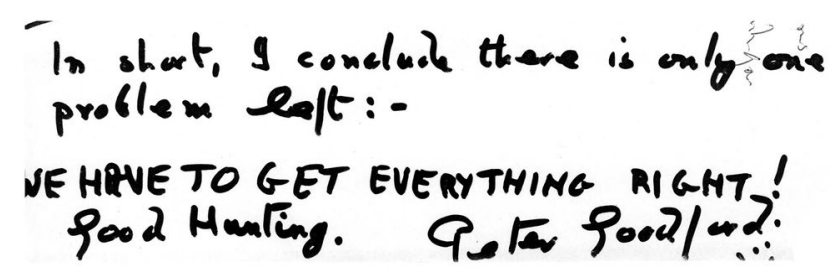

Fig. 5 Peter's concluding statement regarding his set of challenges (Fig. 3) derived during the 1989 meeting at Erice

Publisher's Note Springer Nature remains neutral with regard to jurisdictional claims in published maps and institutional affiliations. 